\title{
Nasopharyngeal Schwannoma
}

\author{
${ }^{1}$ Mayashankar B Vishwakarma, ${ }^{2}$ Sanket D Vakharia, ${ }^{3}$ Vidhyadhar R Borade, ${ }^{4}$ Pooja S Nagare, ${ }^{5}$ Shubhalaxmi A Jaiswal
}

\begin{abstract}
Schwannoma is a rare benign solitary, slowly growing, encapsulated neural tumor arising from the nerve sheath of Schwann cells of the nerves. ${ }^{1}$ They can occur throughout the body with only a handful reported originating in the nasopharynx. These lesions are quiet asymptomatic and malignant transformation rate is negligible. Their clinical presentations are varied and depend on the nerve of origin. Its diagnosis is quite difficult as fine needle aspiration cytology, computerized tomography, and magnetic resonance imaging are of little use. The nasopharynx is, however, a notoriously difficult area to access surgically due to its central location, surrounding facial skeleton and skull base, great vessels, and cranial nerves. Complete surgical excision is treatment of choice and postoperative histopathological examination establishes the final diagnosis. Here we present a rare case of a 25 -year-old male with nasopharyngeal mass whose postoperative histopathological and immunohistochemistry of excised lesion showed a nasopharyngeal schwannoma and discuss the treatment and differential diagnosis for the same.
\end{abstract}

Keywords: Benign nerve cell tumor, Neurilemmoma, Schwannoma.

How to cite this article: Vishwakarma MB, Vakharia SD, Borade VR, Nagare PS, Jaiswal SA. Nasopharyngeal Schwannoma. Int J Otorhinolaryngol Clin 2017;9(2):52-54.

Source of support: Nil

Conflict of interest: None

\section{INTRODUCTION}

Schwannoma was first established as a pathological entity by Verocay in 1908. Stout in 1935 coined the term neurilemmoma. ${ }^{2}$ A schwannoma (neurinoma, neurilemmoma) is a benign, slow-growing solitary tumor that can develop at any age (Most Common 3rd-4th decade) with no predilection for race or sex. ${ }^{3}$ It is composed of Schwann cells, which are neuroectodermal cells that form a sheath around the axons to create the perineurium of the peripheral nerves. Schwannomas can occur throughout the body, and approximately one-third of

\footnotetext{
${ }^{1,4}$ Assistant Professor, ${ }^{2}$ Junior Resident II, ${ }^{3}$ Honorary Associate Professor, ${ }^{5}$ Professor and Head

${ }^{1-5}$ Department of Ear Nose Throat, Dr. Vaishampayan Memorial Government Medical College, Solapur, Maharashtra, India

Corresponding Author: Mayashankar B Vishwakarma Assistant Professor, Department of Ear Nose Throat, Dr. Vaishampayan Memorial Government Medical College, Solapur Maharashtra, India, Phone: +919029453104, e-mail: mshankarv @gmail.com
}

cases (25-40\%) arise in the head or neck; the most frequently affected site among the head and neck region is the 8th cranial nerve. Other locations in the head and neck include the scalp, face, pharynx, parotid gland, middle ear, and external auditory canal. Nasal cavity or nasal sinus schwannomas are rare, accounting only $4 \%$ of the head and neck schwannomas. ${ }^{1,4-8}$ Such schwannomas originate in the extracranial nerves but the exact origin is often obscure. Clinical presentations are varied and nonspecific and depend on the anatomical site of location.

\section{CASE REPORT}

The present case was a 24-year-old male who reported to the Department of Otorhinolaryngology with the complaint of nasal obstruction, nasal discharge, and headache since 1 month, and the symptoms were worsening. Other complaints were bilateral mild ear ache, history of repeated upper respiratory tract infection, and nasal twang to the voice. Past medical and family history were noncontributory. He received multiple courses of antibiotics and anti-inflammatory drugs from the physician without relief of symptoms. On diagnostic nasal endoscopy, a well-circumscribed single smooth surfaced polypoidal mass arising from the posterior wall of nasopharynx was seen. The mass was covered with normal looking mucosa and it was crossing midline. Mass was extending into oropharynx with bulge over soft palate on left side (Fig. 1). Right ear showed Grade II retraction and left ear revealed Grades III/IV retraction. Oral and neck examination records showed no significant findings. Magnetic

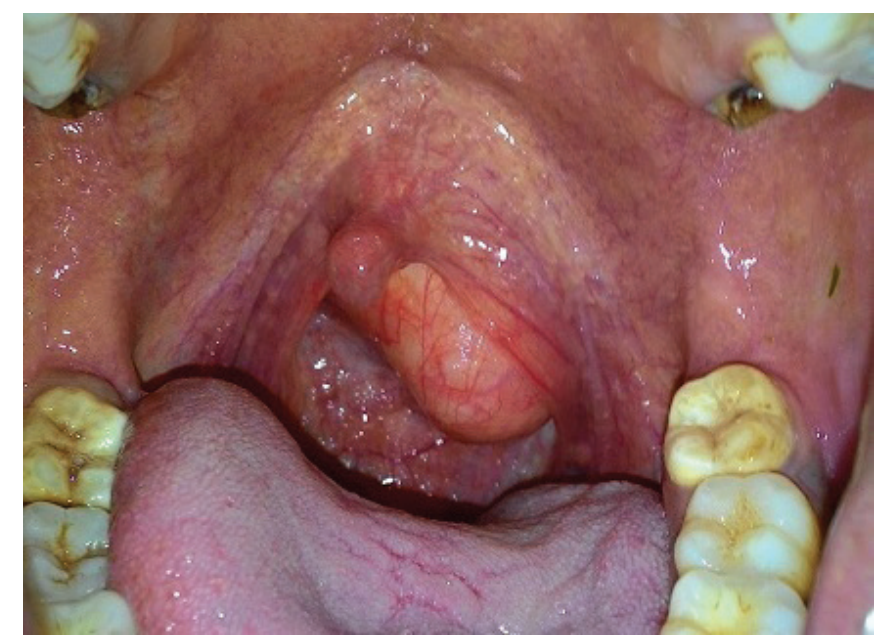

Fig. 1: Nasopharyngeal mass extending into oropharynx with bulge over soft palate 


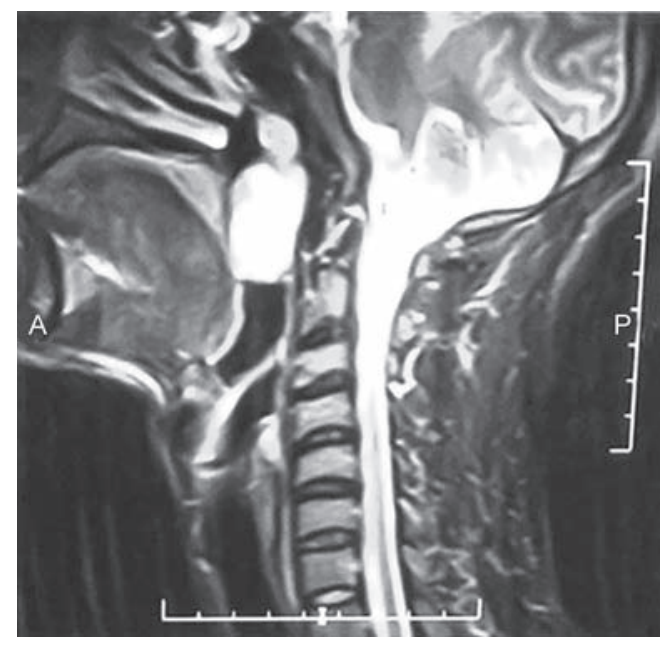

Fig. 2: The MRI heterogeneously enhancing benign polypoidal lesion arising from posterior wall of nasopharynx in the midline without any e/o invasion or intracranial extension

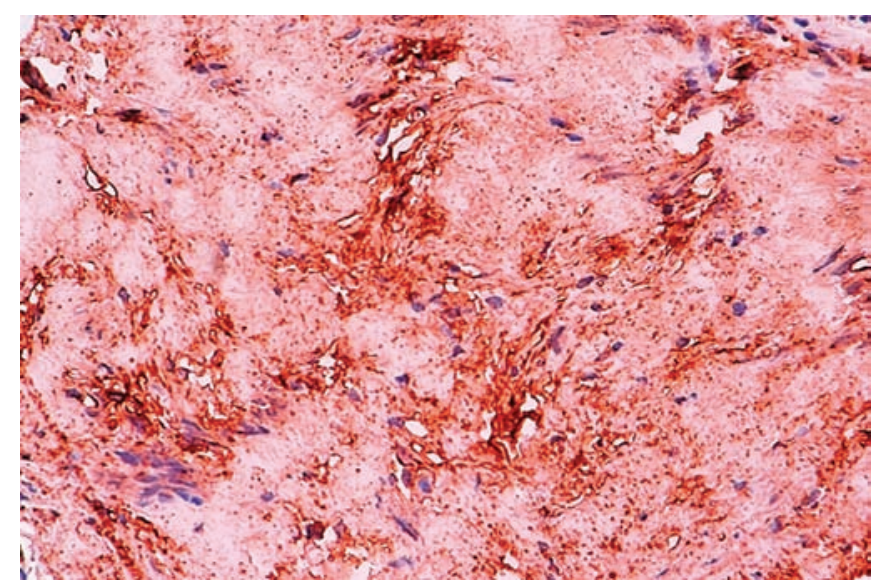

Fig. 4: Immunohistochemical studies show positive S-100 (brown staining)

resonance imaging (MRI) of neck (plain contrast) revealed heterogeneously enhancing benign polypoidal lesion of about $4.3 \times 3.3 \mathrm{~cm}$ arising from the posterior wall of nasopharynx in the midline, with no evidence of any invasion and intracranial extension (Fig. 2). Endoscopy-guided fine needle aspiration cytology (FNAC) was performed, which was not diagnostic so biopsy was performed and it was suggestive of Schwannoma. Endonasal and transoral retroviral approach were used in the present case for completely excising the lesion under general anesthesia.The lesion was completely separated from the surrounding normal tissue. Intraoperatively, the attachment portion of origin of the nerve could not be visible. The mass measured $4 \times 3 \times 2 \mathrm{~cm}$, firm in consistency (Fig. 3). On cut section, the mass was pale yellow gray in color. Microscopy revealed the nasopharyngeal mucosa with capsulated benign nerve sheath cell tumor without breach in capsule. The tumor showed Antoni A and B areas that clinched the diagnosis (Fig. 4). Mass was also reactive for S-100 protein (Fig. 5). Thus, the diagnosis was done histopathologically and immunohistochemically.

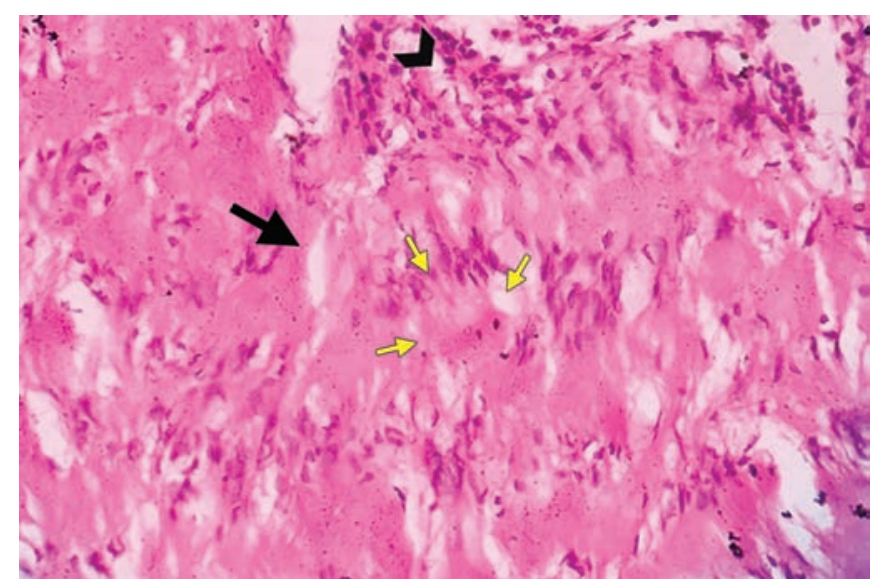

Fig. 3: Histopathology report with Antoni A and Antoni B areas

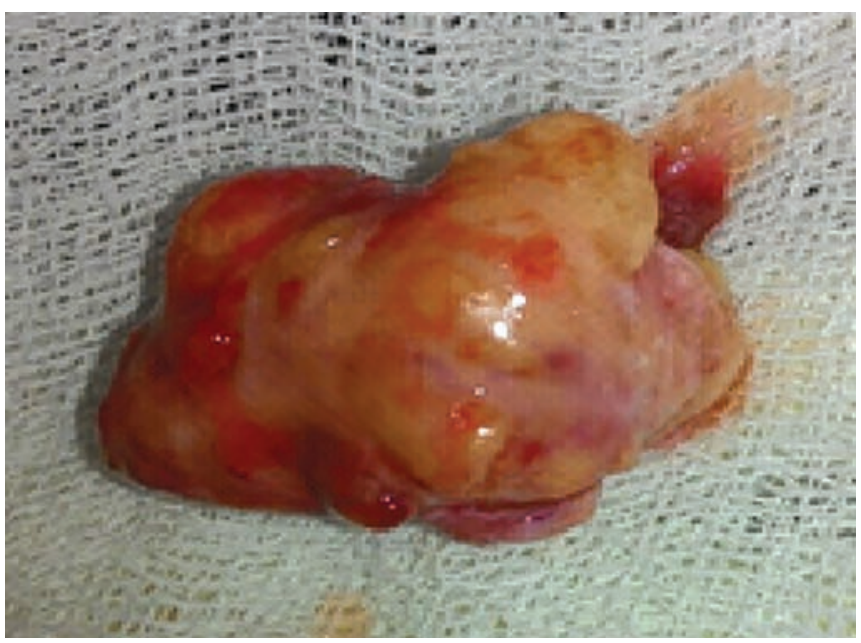

Fig. 5: Tissue specimen

Patient healed completely with uneventful recovery. There was no neurological deficit, and reepithelialization occurred within 15 days.

\section{DISCUSSION}

The neural tumors are known to arise from the neural crest cells; these cells further differentiate to form Schwann cells and sympathicoblasts. The neural tumors, such as neurofibroma and Schwannoma are known to arise from the Schwann cells. Unlike neurofibroma, schwannomas are just attached to the nerves. Schwannomas are benign, encapsulated solitary tumors. Histopathologically, unlike neurofibroma, the schwannomas may, however, show cystic degenerations or hemorrhagic or necrotic changes in the connective tissue stroma. Schwannoma may arise from any cranial or spinal nerve that has a sheath, i.e., it may involve any motor or sensory nerve except the optic and the olfactory nerves as they do not have the Schwann cell sheath. Nasopharyngeal schwannomas may show nonspecific symptoms; however, enlargement of lesion leading to compression of surrounding structures may 
attribute to certain symptoms. Symptoms can include nasal obstruction, epistaxis, and anosmia, together with eustachain tube blockage. Schwannomas behave in a benign fashion. They rarely recur after simple or even incomplete excision, and malignant transformation is extremely rare. Conventionally, open surgical approach is used for these patients, viz., anterior, lateral, and inferior approaches. Among these, the anterior approach of lateral rhinotomy is the most common. The afore-mentioned ways may allow only little access to the lesion; they may even lead to morbidity and compromised cosmesis to the patient. This region showed better visualization with minimally invasive endoscopic resection also further aiding in safety, rapid healing, thus leading to a comparable efficacy to the open approaches. Commonly used investigations like computerized tomography, MRI, and FNAC provide little information about the head and neck schwannomas, thus making it difficult to diagnose. The pathologic findings of schwannoma are quite distinct. Microscopically, schwannoma shows a classic biphasic pattern of more cellular Antoni A areas and paucicellular Antoni B areas. Antoni type A presents a parallel arrangement of fibrocyte-like cells, and Verocay bodies. Antoni B areas are less cellular and may show inflammation, microvacuolation of the intercellular substance, and sometimes degenerative changes may be seen. Flickinger et $\mathrm{al}^{9}$ reported that in most tumors both cell types are present. Since the differential diagnoses included neurofibroma, meningioma, and solitary fibrous tumor as well as schwannoma, we felt immunohistochemical studies were necessary. Differentiating between schwannoma and neurofibroma was especially critical because the latter has greater malignant potential and is locally aggressive. As S-100 protein is expressed by Schwann cells, invariably positivity is seen in all schwannomas. ${ }^{10}$ The present case was strongly positive for S-100 on immunohistochemical investigation; thus, the diagnosis was confirmed. Other diagnostic markers that can aid in diagnosis of schwannomas could be CD56, calretinin, neurofilament, etc. Schwannomas are attached to the nerves; thus, careful dissection and preservation is a must, as the lesion is benign and encapsulated excision is feasible; preservation of the nerve is the only challenge faced.

\section{CONCLUSION}

Extracranial schwannomas present as solitary, asymptomatic masses that are extremely rare and difficult to diagnose. The preoperative diagnosis may be difficult. The definitive diagnosis relies on clinical suspicion and histopathological confirmation after operation. Local recurrence is rare. Complete surgical excision is the treatment of choice. The possibility of nerve injury should be kept in mind.

\section{ACKNOWLEDGMENTS}

Authors would like to thank Dr SA Bolde, Associate Professor, Department of Pathology, Dr Vaishampayan Memorial Government Medical College, Solapur, and Dr Priya A. Bhagde, Junior Resident, Department of Oral Pathology, Government Dental College, Aurangabad.

\section{REFERENCES}

1. Martins MD, Anunciato de Jesus L, Fernandes KP, Bussadori SK, Taghloubi SA, Martins MA. Intra-oral schwannoma: case report and literature review. Indian J Dent Res 2009;20: 121-125.

2. Batsakis JG, Sneig N. Parapharyngeal and retropharyngeal space diseases. Ann Otol Rhinol Laryngol 1989;98:320-321.

3. Higo R, Yamasoba T, Kikuchi S. Nasal neurinoma: case report and review of literature. Auris Nasus Larynx 1993;20:297-301.

4. Das Gupta TK, Brasfield RD, Strong EW, Hajdu SI. Benign solitary schwannomas (neurilemmomas). Cancer 1969;24: 355-366.

5. Wilson JA, McLaren K, McIntyre MA, von Haacke NP, Maran AG. Nerve-sheath tumors of the head and neck. Ear Nose Throat J 1988;67:103-107.

6. Lodding P, Kindblom LG, Angervall L, Stenman G. Cellular schwannoma. A clinicopathologic study of 29 cases. Virchows Arch A Pathol Anat Histopathol 1990;416:237-248.

7. Casadei GP, Scheithauer BW, Hirose T, Manfrini M, Van Houton C, Wood MB. Cellular schwannoma. A clinicopathologic, DNA flow cytometric, and proliferation marker study of 70 patients. Cancer 1995;75:1109-1119.

8. Donnelly MJ, al-Sader MH, Blayney AW. Benign nasal schwannoma. J Laryngol Otol 1992;106:1011-1015.

9. Flickinger FW, Lozano RL, Yuh WTC, Sachs MA. Neurilemmoma of the tongue: MR findings. J Comp Assist Tomogr 1989;13:886-888.

10. Persaud RA, Hajioff D, Chevretton EB. Intranasal schwannoma in a young woman. Int J Clin Pract 2004;58:426-428. 